\title{
Gemcitabine Integrated Nano-Prodrug Carrier System
}

\author{
Seren Hamsici, ${ }^{\dagger}$ Melis Sardan Ekiz,,$^{\dagger}$ Goksu Cinar Ciftci, ${ }^{\dagger}$ Ayse B. Tekinay, ${ }^{*}{ }^{\dagger}$ \\ and Mustafa O. Guler ${ }^{*},+\neq$ (i) \\ ${ }^{\dagger}$ Institute of Materials Science and Nanotechnology, National Nanotechnology Research Center (UNAM), Bilkent University, \\ Ankara, Turkey 06800 \\ ${ }^{\star}$ Institute for Molecular Engineering, University of Chicago, Chicago, Illinois 60637, United States
}

Supporting Information

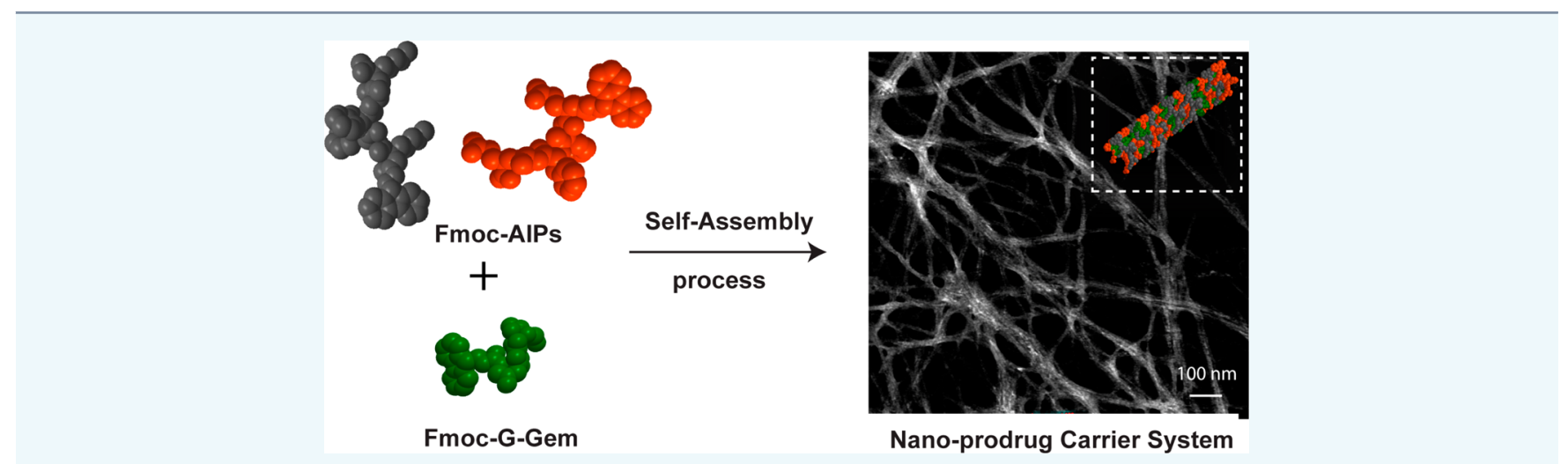

ABSTRACT: Peptide nanomaterials have received a great deal of interest in drug-delivery applications due to their biodegradability, biocompatibility, suitability for large-scale synthesis, high drug-loading capacities, targeting ability, and ordered structural organization. The covalent conjugation of drugs to peptide backbones results in prolonged circulation time and improved stability of drugs. Therapeutic efficacy of gemcitabine, which is used for breast cancer treatment, is severely compromised due to its rapid plasma degradation. Its hydrophilic nature poses a challenge for both its efficient encapsulation into nanocarrier systems and its sustained release property. Here, we designed a new peptide prodrug molecule for the anticancer drug gemcitabine, which was covalently conjugated to the C-terminal of 9-fluorenylmethoxy carbonyl (Fmoc)-protected glycine. The prodrug was further integrated into peptide nanocarrier system through noncovalent interactions. A pair of oppositely charged amyloid-inspired peptides (Fmoc-AIPs) were exploited as components of the drug-carrier system and self-assembled into one-dimensional nanofibers at physiological conditions. The gemcitabine integrated nanoprodrug carrier system exhibited slow release and reduced the cellular viability of $4 \mathrm{~T} 1$ breast cancer cell line in a time- and concentration-dependent manner.

\section{INTRODUCTION}

A wide variety of nanostructured drug carriers have been developed to enhance therapeutic efficacy, increase chemical and biological stability, reduce systemic toxicity, provide controllable drug delivery, and overcome both underdosing and overdosing issues. ${ }^{1}$ The nanocarriers are composed of organic materials including polymers, liposomes, vesicles, peptides, and inorganic materials such as gold nanoparticles and quantum dots to serve as a possible drug vehicle for cancer treatment. ${ }^{2}$ Among them, self-assembled peptide systems hold great importance for drug delivery in terms of their biodegradable and biocompatible properties, suitability for large-scale synthesis, high drug-loading capacities, stimuli responsiveness, and ordered structural organization achieved by noncovalent interactions such as van der Waals, electrostatic, hydrogen bonding, and $\pi-\pi$ stacking. $^{3-5}$ A pair of main strategies are involved in drug delivery approaches: (i) physical encapsulation of drug into the delivery vehicles and (ii) covalent modification of drug with different moieties, called a prodrug strategy. ${ }^{6,7}$ In the former strategy, various peptidic structures were utilized to load either hydrophobic or hydrophilic anticancer drugs that allowed the sustained release of drug together with poor ability for membrane penetration. ${ }^{8,9}$ In addition, self-assembled peptide amphiphile (PA) nanofibers encapsulating a hydrophobic drug, camptothecin, were shown to have great therapeutic potential through passive tumor targeting for both in vitro and in vivo studies. ${ }^{10}$ However, the latter one offers prolonged circulation times and prevents degradation or conversion of drug to its inactive metabolites. ${ }^{11,12}$ For instance, the conjugation of peptides to anticancer drug paclitaxel (PTX) resulted in the prevention of tumor growth in prostate cancer compared to PTX alone due to increased plasma and microsomal half-life. ${ }^{13}$ In another study, PTX was anchored to the cleavable Gly-Phe-Leu-Gly

Received: March 22, 2017

Revised: April 23, 2017

Published: April 25, 2017 
Scheme 1. Synthesis of Fmoc-G-Gem Derivative

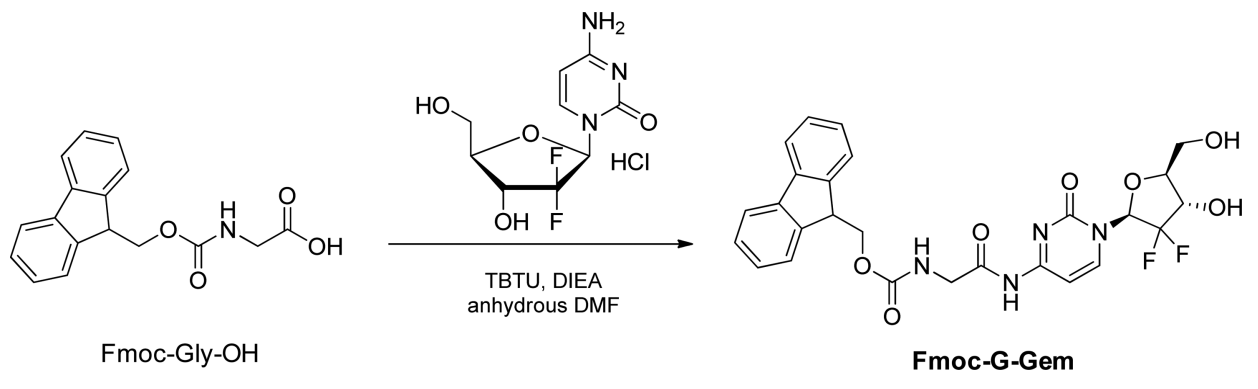

A.

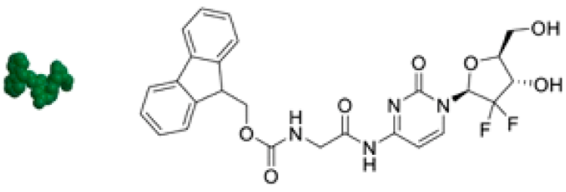

Fmoc-G-Gem

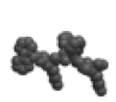

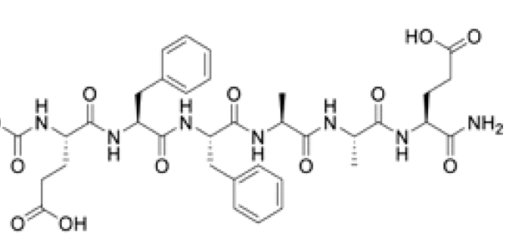

Fmoc-AIP1

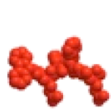

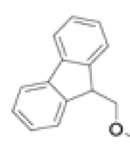

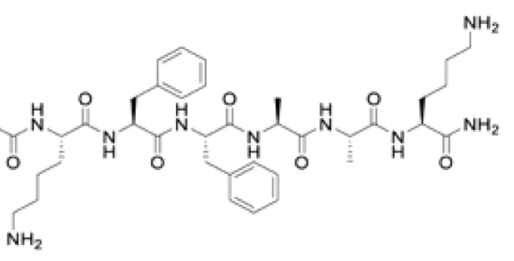

Fmoc-AIP2
B.

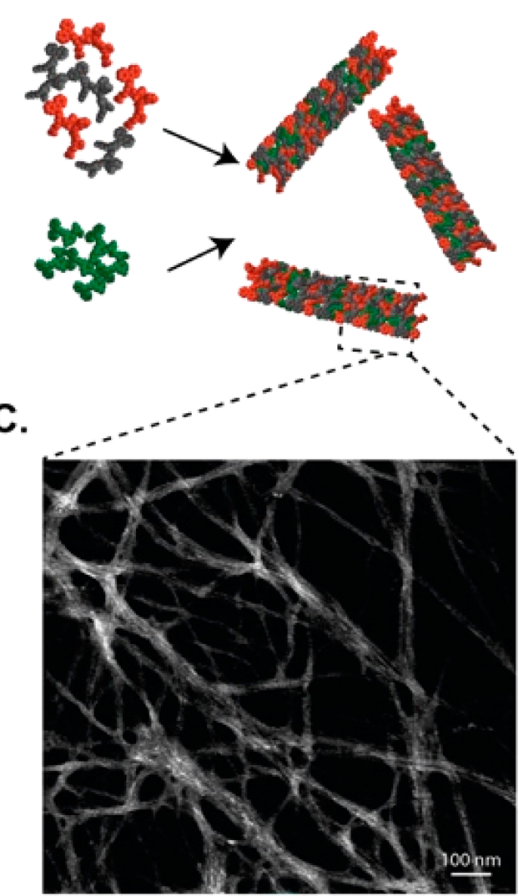

Figure 1. (A) Chemical representations of Fmoc-G-Gem, Fmoc-AIP1 (Fmoc-EFFAAE) and Fmoc-AIP2 (Fmoc-KFFAAK). (B) Schematic representation of co-assembly of Fmoc-AIPs and Fmoc-G-Gem. (C) Scanning transmission electron microscopy image of Fmoc-AIPs with Fmoc-G-Gem nanofibers.

(GFLG) sequence, which allowed its encapsulation into folate receptor (FR)-targeted liposomes to reduce systemic toxicity and lead to increased drug loading for breast cancer treatment. $^{14}$

Gemcitabine, a cytotoxic nucleoside analog, has a unique mode of action that causes DNA chain termination and inhibits DNA synthesis, which further inhibits cell division. ${ }^{15}$ This mode of action results in a broad spectrum of activity in many type of solid tumors. ${ }^{16}$ In addition, gemcitabine, which is Federal Drug Administration approved and clinically used as a chemotherapeutic for the treatment of patients with metastatic breast cancer, provides response rates ranging from 14 to $37 \%$ as a first-line therapy and $23-42 \%$ as a salvage therapy. ${ }^{16-18}$ Furthermore, side effects such as nausea, vomiting, and flu-like symptoms occurred less commonly in breast cancer patients treated with gemcitabine, showing good tolerability of this chemotherapeutic. $^{16,19}$ However, due to the hydrophilic nature of gemcitabine, its activity has been limited by several factors, such as short plasma half-life and poor uptake by cells, because of its inability to cross lipid-rich cell membranes. ${ }^{20,21}$ To overcome these drawbacks, several strategies have been developed for effective delivery of gemcitabine, and most of them are based on the chemical modification of 4-amino group of gemcitabine to eliminate its rapid metabolism driven by cytidine deaminase present in bodily fluids. ${ }^{22}$ Based on these strategies, gemcitabine was conjugated to different moieties such as cleavable linkers, ${ }^{23}$ polymers, ${ }^{24}$ and amphiphilic hybrid systems $^{25}$ to prevent deamination and, hence, to provide improved drug release behavior, longer circulation time, and enhanced therapeutic efficacy against several cancer cell lines. The peptide segment composed of diphenylalanine (FF) residues, which are known to self-assemble into well-ordered structures and play a decisive role in fibril formations due to the interactions between FF aromatic moieties, was systematically studied by several groups, and this ultrashort sequence was further modified by the introduction of 9-fluorenylmethoxy carbonyl (Fmoc) group to strengthen aromatic stacking and the overall self-assembly process. $^{26,27}$ Thus, a molecular model of Fmoc-FF system is more advantageous for controlled drugrelease applications. In this study, we designed Fmocconjugated oppositely charged amyloid inspired peptides, ${ }^{28,29}$ Fmoc-AIP1 (Fmoc-EFFAAE-Am) and Fmoc-AIP2 (Fmoc-KFFAAK-Am), to serve as a possible drug-delivery vehicle by taking advantage of hydrophobic and $\pi-\pi$ stacking 
interactions derived from phenylalanine residues and fluorenyl moieties as well as electrostatic interactions due to the charged residues. Furthermore, gemcitabine was conjugated to Fmocglycine molecules (Fmoc-G-Gem) through amide formation not only to block the 4-amino group of the drug but also to add hydrophobicity and facilitate its integration into the system composed of Fmoc-AIPs. In addition to this smart design strategy, we aimed to combine two main drug-delivery approaches into one system by using both noncovalent integration and prodrug strategies to overcome drawbacks of the drug.

\section{RESULTS AND DISCUSSION}

Gemcitabine-mediated breast cancer therapy faces several obstacles, such as high hydrophilicity and rapid plasma metabolism upon its enzymatic conversion in the blood, liver, and tumor tissue. ${ }^{20}$ We hypothesized that protection of amino group of gemcitabine would prevent these drawbacks and improve the stability and cytotoxic activity of gemcitabine when formed into a prodrug and incorporated into a peptide-based carrier system. For this purpose, the 4-N position of gemcitabine was protected by conjugating it to the $\mathrm{C}$-terminal of Fmoc-glycine molecules to afford Fmoc-G-Gem (Scheme 1 and Figures S1 and S2). For the delivery of prodrug, amyloidinspired Fmoc-AIP1 and Fmoc-AIP2 were used as the twocomponent-carrier system (Figure 1A). The addition of Fmoc groups enhances the hydrophobicity of the system and the selfassembly of fiber formation governed by hydrophobic interactions. $^{30}$

The peptides were synthesized by using solid-phase peptide synthesis strategy, and their chemical structures were verified by liquid chromatography and mass spectrometry (Figure S3). The hydrophobic nature of Fmoc-G-Gem enables the stacking of aromatically rich oppositely charged Fmoc-AIPs (Figure 1B). It is clear from the scanning transmission electron microscope (STEM) images that while the co-assembled system of Fmoc-AIPs showed a high-aspect-ratio nanofiber formation (Figure S4A), only Fmoc-G-Gem did not exhibit any structural organization (Figure S4B). Besides hydrophobic and $\pi-\pi$ interactions among Fmoc groups and phenylalanine residues, electrostatic interactions between the hydrophilic Lys and Glu moieties led to the formation of one-dimensional selfassembled nanofibers (Figure 1C).

In aqueous solution, while individual molecules (FmocAIP1, Fmoc-AIP2, and Fmoc-G-Gem) have a critical aggregation concentration of ca. $50 \mu \mathrm{M}$ (Figure S5A), Fmoc-AIPs (the critical aggregation concentration is ca. 5 $\mu \mathrm{M})$ self-assemble into peptide nanofibers composed of a hydrophilic outer shell exposed to the aqueous phase and a hydrophobic inner core interacting with Fmoc-G-Gem molecules, suggesting that $\pi-\pi$ interactions and packing effects between both Fmoc units and phenylalanine residues reinforce the self-assembly of these hydrophobic units (Figure S5B). Based on the concentrations determined by Nile red assay, which is a fluorescent solvatochromic probe, to determine critical aggregation concentration of supramolecular systems, the secondary structures of Fmoc-AIPs and Fmoc-AIPs with Fmoc-G-Gem were assessed using circular dichroism (CD) and Congo Red (CR) and Fourier transform-infrared (FTIR) analysis.

The CD spectra displayed negative bands at 225 and $221 \mathrm{~nm}$ for Fmoc-AIPs and Fmoc-AIPs with Fmoc-G-Gem (Figure $2 A)$, respectively, which showed a red shift relative to typical $\beta$ -
A.

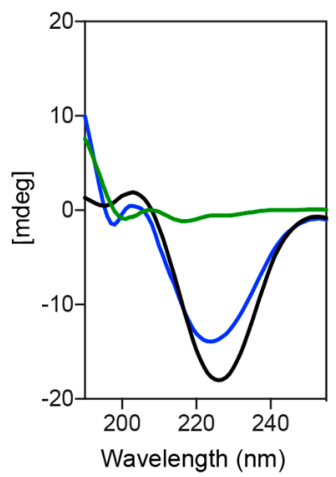

B.

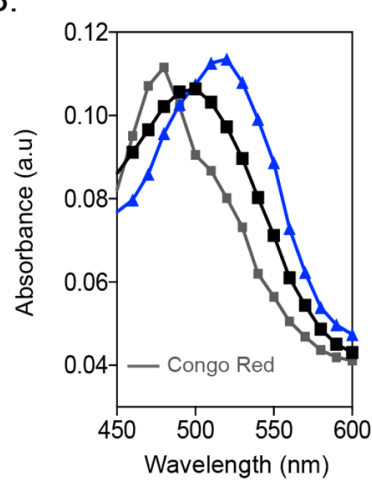

C.

Fmoc-AIPs
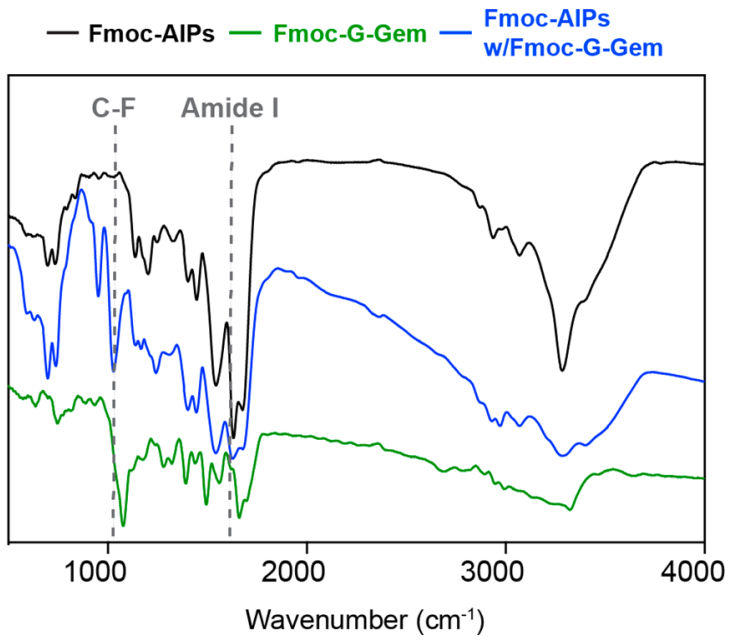

Figure 2. Secondary structure analysis of Fmoc-AIPs, Fmoc-GGem, and Fmoc-AIPs with Fmoc-G-Gem conducted by (A) circular dichroism. (B) Congo Red assay at physiological conditions. (C) FT-IR analysis using the dried samples.

sheet spectrum with a minimum at $216 \mathrm{~nm}$ due to twisted structure, $^{31,32}$ while Fmoc-AIP1 or Fmoc-AIP2 alone preserved their random coil structure (Figure S6) at physiological conditions. Amyloid fibril detection was quantitatively assessed by $\mathrm{CR}$ assay, which lies parallel to the fibril axis and induced a red shift in the absorption maximum from 484 to 500 and $520 \mathrm{~nm}$ for Fmoc-AIPs and Fmoc-AIPs with Fmoc$\mathrm{G}-\mathrm{Gem}$, respectively, as a result of interaction with $\beta$-sheet rich amyloid fibrils (Figure 2B). ${ }^{33}$ The $\beta$ - sheet arrangements of Fmoc-AIPs are in agreement with FT-IR analysis. The FTIR spectra of self-assembled Fmoc-AIPs and Fmoc-AIPs with Fmoc-G-Gem showed an amide I band between 1620 and $1640 \mathrm{~cm}^{-1}$ associated with $\mathrm{C}=\mathrm{O}$ stretching, while the peak that appeared in the amide II band at $1546 \mathrm{~cm}^{-1}$ was attributed to $\mathrm{N}-\mathrm{H}$ bending, which suggests the availability of intermolecular hydrogen-bonded structure in the system. ${ }^{31}$ The Fmoc-G-Gem characteristic peak for C-F stretching appeared at $1079 \mathrm{~cm}^{-1}$, and its integration within selfassembled Fmoc-AIPs resulted in a red shift to $1031 \mathrm{~cm}^{-1}$, while Fmoc-AIPs did not show any similar peaks in that region (Figure 2C). ${ }^{34}$ X-ray diffraction patterns of Fmoc-AIPs and Fmoc-AIPs with Fmoc-G-Gem supported the results acquired from FT-IR spectroscopy, which showed evidence of the $\beta$-sheets (broad peak at $2 \theta=19.06^{\circ}, d$ spacing of $4.8 \AA$ ) observed in both groups (Figure S7). ${ }^{35}$

After the confirmation of the integration of prodrug molecule into amyloid-inspired nanofibers, prodrug release studies were 
carried out at acidic environment to mimic extracellular matrix of tumor tissue. ${ }^{36}$ Major factor that limits the encapsulation of pharmaceuticals to peptide-based nanocarriers is their inability to be entrapped within the system due to lack of interactions between drug and peptide. ${ }^{37}$ Therefore, in our system, the Fmoc moiety of Gem enables the avoidance of the hydrophilic nature of Gem and enhances the noncovalent interactions. The fibrillar network of Fmoc-AIPs encapsulated hydrophobic Fmoc-G-Gem and released it in a controlled manner. As shown in Figure 3, Fmoc-AIPs have a stable release profile.

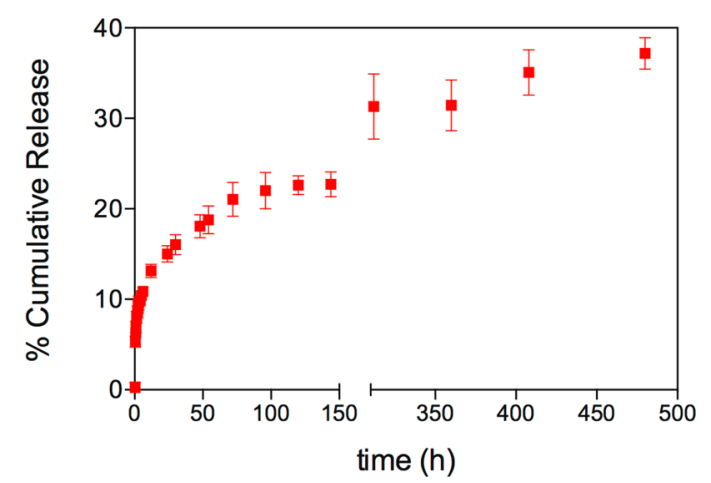

Figure 3. Release behavior of Fmoc-G-Gem through Fmoc-AIPs for $480 \mathrm{~h}$ (20 days) at $\mathrm{pH}$ 5.5.

The release of Fmoc-G-Gem from Fmoc-AIPs exhibited a biphasic pattern that was characterized by a fast initial release during the first $15 \mathrm{~h}$, followed by a slower controlled release. As a cumulative release of the third week, even in acidic conditions, $37 \%$ of Fmoc-G-Gem was released.
Dose-dependent cytotoxicity evaluation of Fmoc-AIPs by using 4T1 breast cancer cell line revealed that the Fmoc-AIPs carrier system is biocompatible at concentrations below 125 $\mu \mathrm{M}$ after both 24 and $48 \mathrm{~h}$ (Figure S8). Fmoc-G-Gem and Gem-only groups were also examined by Alamar blue assay, and their $\mathrm{IC}_{50}$ values were calculated as $12.23 \pm 1.44$ and $11.67 \pm$ $1.46 \mu \mathrm{M}$ for $24 \mathrm{~h}$ and $1.25 \pm 1.14$ and $6.77 \pm 2.11 \mu \mathrm{M}$ for $48 \mathrm{~h}$, respectively.

Because the doubling time of $4 \mathrm{~T} 1$ cells is $25 \mathrm{~h}^{38}$ and gemcitabine disrupts DNA strand elongation during DNA replication, ${ }^{39}$ the more-pronounced cytotoxic effect of both Fmoc-G-Gem and Gem-only treatments was observed at 48 $\mathrm{h}$ compared to the results from $24 \mathrm{~h}$. The biodegradability of peptide assemblies and supramolecular architectures via different proteases has been studied in different studies. ${ }^{40,41}$ Under the nonspecific enzymatic activity of proteases, peptide assemblies can be easily degraded into the building blocks at physiological conditions. ${ }^{42,43}$ It is also possible to integrate sequence specific cleavable domains to control the biodegradability of peptide assemblies under specific protease activity. 44,45 In our approach, the 4-N position of gemcitabine was chemically conjugated to the C-terminal of Fmoc-glycine molecules through amide bond formation, and the nonspecific proteolytic degradation of the nanocarrier system could facilitate release of the drug molecules under cellular metabolic activity. The promoted cytotoxic effect determined via cellular viability experiments also pointed us toward the enhanced bioavailability and proper release of the active molecules from the carrier system. The cytotoxic effect of integrated Fmoc-GGem was also investigated for 24 and $48 \mathrm{~h}$ (Figure S9) and supported the drug-release behavior discussed above. During the first $24 \mathrm{~h}, 15 \%$ of Fmoc-G-Gem was released through the

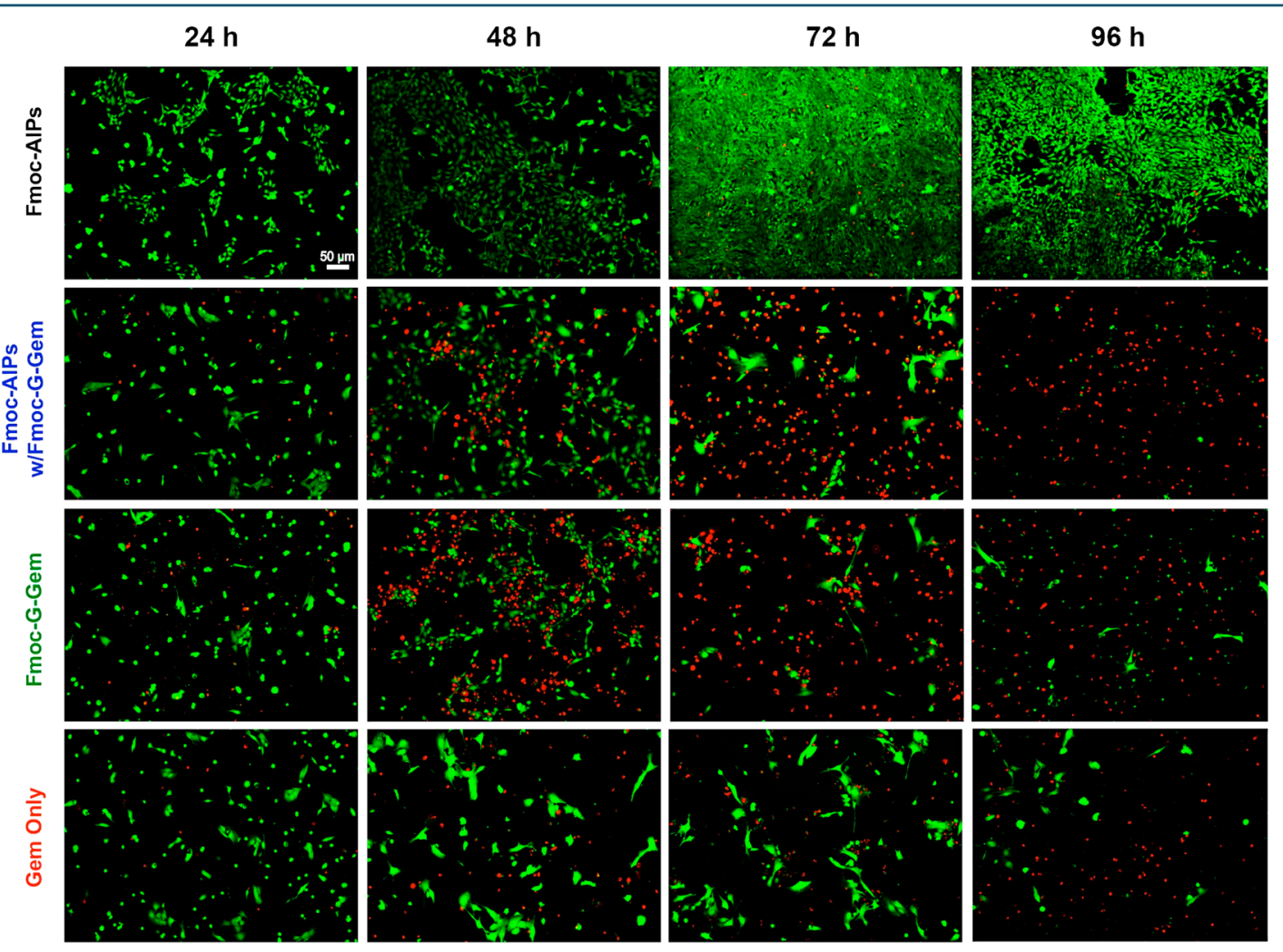

Figure 4. Representative images of live (green) and dead (red) assay of 4T1 cells treated with Fmoc-AIPs, Gem only, Fmoc-G-Gem, and FmocAIPs with Fmoc-G-Gem during 4 days with a 1 day interval. 
$24 \mathrm{~h}$

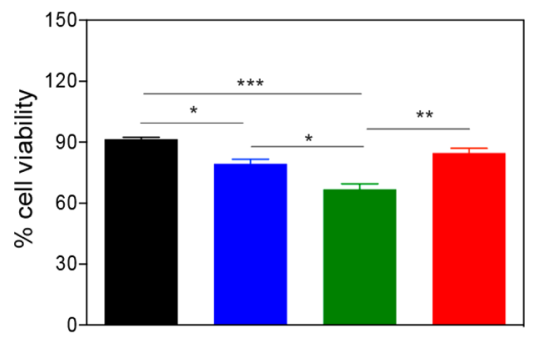

$72 \mathrm{~h}$

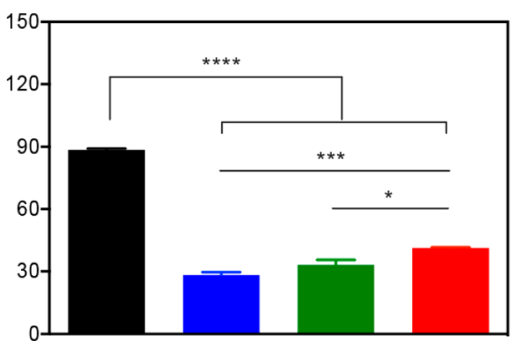

$48 \mathrm{~h}$

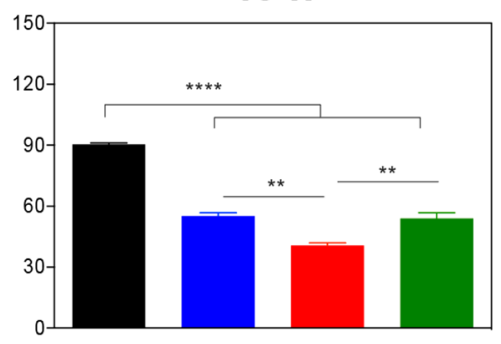

$96 \mathrm{~h}$

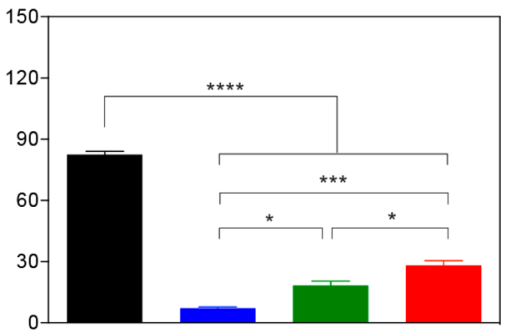

Figure 5. Rate of cellular viability for 24, 48, 72, and 96 h. Fmoc-AIPs (black), Fmoc-AIPs with Fmoc-G-Gem (blue), Fmoc-G-Gem (green), and Gem-only (red) treatments. Values represent mean \pm standard error of means $(* * * *, p<0.0001 ; * * *, p<0.001 ; * *, p<0.01$; and $*, p<$ $0.005)$.

Fmoc-AIP nanocarrier system at $\mathrm{pH} 5.5$, and the $\mathrm{IC}_{50}$ value for integrated Fmoc-G-Gem was $23.98 \pm 4.46 \mu \mathrm{M}$ for $24 \mathrm{~h}$ (Figure S9), meaning that the concentration of integrated Fmoc-G-Gem should be within this range to reach the $\mathrm{IC}_{50}$ of free Fmoc-G-Gem, which is $12.23 \pm 1.44 \mu \mathrm{M}$ at $24 \mathrm{~h}$.

The live-dead assay was performed to demonstrate the effect of both Fmoc-G-Gem and Fmoc-AIPs with FmocG-Gem at a 1 day interval during 4 days of incubation (Figure 4). Although a significant difference was not observed between the viability of the cells treated with Fmoc-AIPs with FmocG-Gem during $72 \mathrm{~h}$, strikingly, the Fmoc-G-Gem-integrated Fmoc-AIP system showed a more-cytotoxic effect on 4T1 cells after $96 \mathrm{~h}$ of culture than that of individual Fmoc-G-Gem and Gem-only groups at the end of fourth day due to the sustained release behavior (Figure 5).

\section{CONCLUSIONS}

In conclusion, we have designed and characterized a new nanocarrier drug-delivery system that combined two drugdelivery strategies to develop an effective prodrug-carrier system. The conjugation of gemcitabine to Fmoc-glycine was followed by the noncovalent integration of Fmoc-G-Gem into Fmoc-AIPs, which self-assembled into one-dimensional nanofibers. The prodrug dosage can be adjusted without disrupting the self-assembly process, and supramolecular architecture formed by the binary self-assembled amyloidinspired peptide nanofiber system enables the release of the drug in a controlled fashion and provides stability due to the preservation of the 4-N position of the drug. The gemcitabineintegrated nanoprodrug carrier system showed significant reduction in cell viability of the breast cancer cell line without inducing any of the toxicity associated with Fmoc-AIPs. The strategy demonstrated in this work not only provides a promising approach as an alternative therapy for breast cancer treatment but could also be explored for the delivery of other hydrophilic drugs. It provides new opportunities for highly therapeutic drugs with modest clinical benefit due to delivery challenges and rapid plasma metabolism caused by enzymatic degradation.

\section{EXPERIMENTAL SECTION}

Materials. 9-Fluorenylmethoxycarbonyl-protected amino acids, $\left[4-\left[\alpha-\left(2^{\prime}, 4^{\prime}\right.\right.\right.$-dimethoxyphenyl $)$ Fmoc aminomethyl $]$ phenoxy] acetamidonorleucyl-MBHA resin (Rink amide MBHA resin), Wang resin, 2-(1H-benzotriazol-1-yl)-1,1,3,3tetramethyluronium hexafluorophosphate (HBTU), and $O$ (Benzotriazol-1-yl)- $N, N, N^{\prime}, N^{\prime}$-tetramethyluronium tetrafluoroborate (TBTU) were purchased from NovaBiochem. Gemcitabine was purchased from Carbosynth. Lauric acid and $\mathrm{N}, \mathrm{N}$ diisopropylethylamine (DIEA) were purchased from Merck. Other chemicals were purchased from Alfa Aesar or SigmaAldrich and used without any purification. Deionized water (resistance of $18 \mathrm{M} \Omega . \mathrm{cm}$ ) was used during the experiments.

Synthesis of Gemcitabine Conjugated Amino Acid, Fmoc-G-Gem. The compound was synthesized based on a previously published procedure with slight modifications. Fmoc-Gly-OH (149 mg, $0.5 \mathrm{mmol}$ ) dissolved in anhydrous DMF (3-4 mL) was cooled to $0{ }^{\circ} \mathrm{C}$. TBTU $(215 \mathrm{mg}, 0.66$ $\mathrm{mmol})$ and DIEA ( $165 \mu \mathrm{L}, 1.08 \mathrm{mmol})$ were added individually into the solution and stirred for $30 \mathrm{~min}$. Then, gemcitabine $(165 \mathrm{mg}, 0.58 \mathrm{mmol})$ was added and stirred for another $30 \mathrm{~min}$ at $0{ }^{\circ} \mathrm{C}$. The reaction mixture was left at room temperature and stirred for $18 \mathrm{~h}$. The compound was concentrated in a rotary evaporator and purified with column chromatography (1:9 $\mathrm{MeOH} / \mathrm{DCM}, \mathrm{Rf}=0.3$, crude yield: $61 \%) .{ }^{1} \mathrm{H}$ NMR (400 MHz, DMSO- $\left.d_{6}, \delta\right): 8.27(\mathrm{~d}, J=7.6 \mathrm{~Hz}, 1 \mathrm{H}), 7.90(\mathrm{~d}, J=7.5$ $\mathrm{Hz}, 2 \mathrm{H}), 7.73$ (d, $J=7.4 \mathrm{~Hz}, 2 \mathrm{H}), 7.65(\mathrm{t}, J=6.0 \mathrm{~Hz}, 1 \mathrm{H}), 7.43$ $(\mathrm{t}, J=7.4 \mathrm{~Hz}, 2 \mathrm{H}), 7.34(\mathrm{t}, J=7.4 \mathrm{~Hz}, 2 \mathrm{H}), 7.23(\mathrm{~d}, J=7.7 \mathrm{~Hz}$, $1 \mathrm{H}), 6.34(\mathrm{~d}, J=6.4 \mathrm{~Hz}, 1 \mathrm{H}), 6.19(\mathrm{~m}, 1 \mathrm{H}), 5.31$ (brs, $1 \mathrm{H})$, $4.32(\mathrm{~m}, 2 \mathrm{H}), 4.25-4.20(\mathrm{~m}, 2 \mathrm{H}), 3.90(\mathrm{~m}, 2 \mathrm{H}), 3.82(\mathrm{~m}, 1 \mathrm{H})$, $3.62(\mathrm{~m}, 2 \mathrm{H}), 3.15(\mathrm{~m}, 1 \mathrm{H}) .{ }^{13} \mathrm{C}$ NMR $\left(100 \mathrm{MHz}, \mathrm{DMSO}-d_{6}\right.$, $\delta): 171.25,163.14,157.03,154.59,145.43,144.27,141.20$, $128.11,127.55,125.68,120.58,96.32,81.49$, 66.25, 55.27, $54.04,47.08,44.91,42.28$. Electrospray ionization time-of-flight 
high-resolution mass spectrometry $(\mathrm{m} / z):[\mathrm{M}+\mathrm{H}]^{+}$calcd for $\mathrm{C}_{26} \mathrm{H}_{24} \mathrm{~F}_{2} \mathrm{~N}_{4} \mathrm{O}_{2}$, 543.1613; found, 543.1702; $[\mathrm{M}+\mathrm{Na}]^{+}$: 565.1518 .

Synthesis and Characterization of Fmoc-AIPs. Fmocprotected amyloid-inspired peptides were synthesized by using a solid-phase peptide synthesis method. Fmoc-AIP1 and Fmoc-AIP2 peptides were prepared on a $0.5 \mathrm{mmol}$ scale by repeated amino acid couplings using Fmoc-protected amino acid (2 equiv), HBTU (1.95 equiv), and DIEA (3 equiv). MBHA Rink amide resin was used as solid support to construct the peptides. A Fmoc-protecting group of amino acids, except that of the final residue, was removed through treatment with $20 \%$ piperidine-DMF solution for $20 \mathrm{~min}$. Cleavage of the peptides from resin and deprotection of acid-labile-protected amino acids were carried out with a mixture of TFA, TIS, and $\mathrm{H}_{2} \mathrm{O}$ at a ratio of 95:2.5:2.5 for $2.5 \mathrm{~h}$. Excess TFA and organic solvents were removed by rotary evaporation under reduced pressure, and the remaining peptide was precipitated using diethyl ether at $-20{ }^{\circ} \mathrm{C}$ overnight. The centrifuged white peptide precipitate was dissolved in water and freeze-dried for 3 days. Positively charged Fmoc-AIP2 was treated with $1 \mathrm{mM}$ $\mathrm{HCl}$ and freeze-dried again to remove residual TFA. The peptides were identified and analyzed by reverse-phase highperformance liquid chromatography monitored at $220 \mathrm{~nm}$ on an Agilent 6530 accurate-mass quadrupole time-of-flight mass spectrometry device equipped with an Agilent 1200 highperformance liquid chromatograph. While an Agilent Zorbax Extend-C18 $(50 \times 2.1 \mathrm{~mm})$ column with a mobile phase of a water and acetonitrile mixture $\left(0.1 \% \mathrm{NH}_{4} \mathrm{OH}\right)$ was used during the identification of negatively charged Fmoc-AIP1, a Phenomenex Luna $3 \mu \mathrm{C} 8100 \mathrm{~A}(50 \times 3.00 \mathrm{~mm})$ column as the stationary phase and a water-acetonitrile gradient with a $0.1 \%$ volume of formic acid as the mobile phase were used to elucidate the positively charged Fmoc-AIP2.

Preparation of Fmoc-G-Gem Integrated Fmoc-AIPs Carrier System. Fmoc-AIP1 and Fmoc-AIP2 solutions at a $0.005 \%(\mathrm{w} / \mathrm{v})$ concentration were prepared at $\mathrm{pH} 7.4$ in water. The stock solution of Fmoc-G-Gem (18.5 mM) was dissolved in DMSO. The stock drug solution was first mixed with positively charged Fmoc-AIP2, and then co-assembly was triggered upon addition of the negatively charged Fmoc-AIP1 at physiological conditions at a 1:1 volumetric ratio. The final Fmoc-G-Gem concentration within Fmoc-AIPs was adjusted to $60 \mu \mathrm{M}$, and the final DMSO concentration in the system was $1 \%(\mathrm{w} / \mathrm{v})$.

Critical Aggregation Concentration Determination. To determine the transition phase between peptide assemblies and to control the morphologies, hydrophobic Nile red (9diethylamino-5-benzo $[\alpha]$ phenoxazinone) fluorescent probe assay was applied to the peptide solutions (ranging from 1 $\mathrm{mM}$ to $0.244 \mu \mathrm{M}$ ) prepared in distilled water at around $\mathrm{pH}$ 7. A $1.25 \mathrm{mM}$ stock solution of Nile red was prepared in ethanol (1 $\mathrm{mL}$ ) and then diluted to $78.12 \mu \mathrm{M}$ by using ethanol. The peptide solutions prepared at different concentrations were mixed with the same amount of the dye solution and incubated overnight at room temperature. The final Nile red concentration in the mixtures was $250 \mathrm{nM}$, and $0.31 \%(\mathrm{v} / \mathrm{v})$ ethanol was present in the solutions. A Cary Eclipse spectrophotometer was used to collect emission spectra between 580 and $750 \mathrm{~nm}$ at an excitation of $550 \mathrm{~nm}$.

FT-IR spectroscopy. FT-IR (Bruker-Tensor 37) was used for the collection of IR spectra of the samples. Only Fmoc-G-Gem, only Fmoc-AIPs, and Fmoc-G-Gem- encapsulated Fmoc-AIPs were mixed with potassium bromide to prepare the pellets by pressing. The IR spectra were recorded between 4000 and $400 \mathrm{~cm}^{-1}$ at a resolution of $4 \mathrm{~cm}^{-1}$ with 64 scans per sample.

Circular Dichroism. A $0.5 \%(\mathrm{w} / \mathrm{v})$ solution of Fmoc-AIP1 and Fmoc-AIP2 $(5.35 \mathrm{mM})$ were prepared in water. The $\mathrm{pH}$ adjustment of Fmoc-AIP1 was performed by using $\mathrm{NaOH}$ and kept at $\mathrm{pH}$ 8.0, while Fmoc-AIP2 was around $\mathrm{pH} 6.5$ in water. Solutions were mixed at a $1: 1$ ratio $(200 \mu \mathrm{L}$ of Fmoc-AIP 1 and $200 \mu \mathrm{L}$ of Fmoc-AIP2) and held at room temperature for $6 \mathrm{~h}$ to achieve co-assembly. Upon mixing with a 1:1 molar ratio, the $\mathrm{pH}$ of Fmoc-AIPs was at around 7.4. Prior to analysis, solutions were diluted up to $60 \mu \mathrm{M}$, and the final Fmoc-GGem concentration within the system was $20 \mu \mathrm{M}$. A Jasco J-815 $\mathrm{CD}$ spectrophotometer was used for $\mathrm{CD}$ analysis, and measurements were taken between 300 and $190 \mathrm{~nm}$ with a $0.1 \mathrm{~nm}$ data pitch.

X-ray Powder Diffraction. The $\beta$-sheet structure of Fmoc-AIPs and Fmoc-G-Gem with Fmoc-AIPs was investigated through a PANanalytical X'Pert powder diffractometer operating at $45 \mathrm{kV}$ and $40 \mathrm{~mA}$. Samples were ground and dispersed homogeneously onto the holder, and analyses were conducted between $2 \theta=15^{\circ}-30^{\circ}$.

Scanning Transmission Electron Microscopy Imaging. For STEM imaging of Fmoc-AIPs, Fmoc-G-Gem with Fmoc-AIPs, and Fmoc-G-Gem, samples were dropped onto a transmission electron microscopy (TEM) grid, kept for 15 min, washed with water, and stained with $2 \%(\mathrm{w} / \mathrm{v})$ uranyl acetate. After drying, a FEI Tecnai G2 F30 STEM instrument was used for imaging.

Congo Red Staining. Stock Congo red dye (SigmaAldrich) was dissolved in water at a final concentration of 1 $\mathrm{mM}$. For sample preparation, $100 \mu \mathrm{L}$ of $60 \mu \mathrm{M}$ Fmoc-AIP1 and $100 \mu \mathrm{L}$ of $60 \mu \mathrm{M}$ Fmoc-AIP2 were mixed at $\mathrm{pH} 7$, and $2 \mu \mathrm{L}$ of stock Congo red solution was added into mixtures. For the Fmoc-AIPs with Fmoc-G-Gem system, $1 \mu \mathrm{L}$ of $4 \mathrm{mM}$ Fmoc-G-Gem solution was mixed with Fmoc-AIPs at a final concentration of $20 \mu \mathrm{M}$ before adding Congo red. The control group of only Congo red dye was also prepared at a final concentration of $10 \mu \mathrm{M}$. After $2 \mathrm{~h}$ of incubation, mixtures were analyzed through Spectramax M5 microplate reader for absorbance measurements between 450 and $600 \mathrm{~nm}$.

Controlled Release Behavior. The release of Fmoc-GGem from Fmoc-AIPs was investigated under physiological conditions ( $\mathrm{pH}$ 7.4). First, 1\% (w/v) Fmoc-AIP1 and FmocAIP2 were dissolved in water. Initially, $3 \mu \mathrm{L}$ of Fmoc-G-Gem (360 mM, dissolved in DMSO) was added to $150 \mu \mathrm{L}$ of positively charged Fmoc-AIP2 solution, and then co-assembly of the system was triggered after the addition of $150 \mu \mathrm{L}$ of Fmoc-AIP1 solution. Fmoc-AIPs and Fmoc-AIPs with Fmoc-G-Gem were formed at the bottom of the quartz cells and incubated overnight at $37^{\circ} \mathrm{C}$. For Fmoc-AIPs with Fmoc-G-Gem groups, the final Fmoc-G-Gem concentration was adjusted to $3.6 \mathrm{mM}$ within the system. The release of Fmoc-G-Gem from Fmoc-AIPs was investigated in PBS buffer $\left(2700 \mu \mathrm{L}, \mathrm{pH} 7.4\right.$ at $\left.37^{\circ} \mathrm{C}\right)$. At regular time intervals, samples were withdrawn and analyzed using a Cary 5000 UVvis spectrophotometer between 230 and $400 \mathrm{~nm}$. Only FmocAIPs, at $\mathrm{pH}$ 7.4, were used as a baseline and subtracted from Fmoc-AIPs with Fmoc-G-Gem to discard the effect of the peptide. The maximum Fmoc-G-Gem absorbance at $260 \mathrm{~nm}$ was converted into the concentration by calibration curve. Then, the cumulative release of Fmoc-G-Gem was calculated. 
Cell Culturing and Maintenance. The 4T1 breast cancer cell line was maintained in Dulbecco's modified Eagle's medium containing $1 \%$ antibiotics and $10 \%$ fetal bovine serum at $37^{\circ} \mathrm{C} /$ $5 \% \mathrm{CO}_{2}$.

Dose Determination. In vitro cytotoxicity of Gem-only, Fmoc-AIPs, Fmoc-G-Gem, and Fmoc-AIPs with FmocG-Gem treatments was evaluated by Alamar Blue viability test. Briefly, cells were seeded in $100 \mu \mathrm{L}$ of culture medium $\left(8 \times 10^{3}\right.$ cells per well) in 96 well plates for 24 and $48 \mathrm{~h}$. The cells were then exposed to a series of $200 \mu \mathrm{L}$ samples of Fmoc-G-Gem, Fmoc-AIPs, Gem-only, or Fmoc-AIPs with Fmoc-G-Gem solutions of different concentrations in cell culture medium. After incubation for 24 and $48 \mathrm{~h}$, the medium was discarded, and $10 \%(\mathrm{v} / \mathrm{v})$ Alamar blue in cell medium $(200 \mu \mathrm{L})$ was added to each well and incubated for 2-3 h. Finally, absorbance was measured at $570 \mathrm{~nm}$ with a Spectramax M5 microplate reader, and $\mathrm{IC}_{50}$ values were calculated by Graphpad Prism software.

Cell Viability. To determine the effect of Fmoc-G-Gem on $4 \mathrm{~T} 1$ apoptosis, a live-dead assay kit (Invitrogen), which determines esterase activity and plasma membrane integrity, was used. Briefly, cells were seeded in $100 \mu \mathrm{L}$ of culture medium $\left(2.5 \times 10^{3}\right.$ cells per well $)$ in 96 well plates, incubated for $1 \mathrm{~h}$ at $37^{\circ} \mathrm{C}$, and then treated with $200 \mu \mathrm{L}$ of Gem-only (20 $\mu \mathrm{M})$, Fmoc-AIPs $(60 \mu \mathrm{M})$, Fmoc-G-Gem $(20 \mu \mathrm{M})$, and Fmoc-AIPs with Fmoc-G-Gem in cell culture medium for 24, 48, 72, and $96 \mathrm{~h}$. Cell viability was determined under an inverted fluorescence microscope by counting live (green) and dead (red) cells.

Statistical Analysis. All experiments were independently repeated at least twice with at least three replicates for each experimental group. All quantitative results were expressed as \pm standard error of means. Statistical analyses were carried out by one-way or two-way analysis of variance (ANOVA), whichever is applicable.

\section{ASSOCIATED CONTENT}

\section{S Supporting Information}

The Supporting Information is available free of charge on the ACS Publications website at DOI: 10.1021/acs.bioconjchem.7b00155.

Figures showing ${ }^{1} \mathrm{H}$ and ${ }^{13} \mathrm{C}$ nuclear magnetic resonance and mass spectra of Fmoc-G-Gem; liquid chromatography-mass spectrometry results of Fmoc-AIPs; scanning transmission electron microscopy images of Fmoc-AIPs and Fmoc-AIPs with Fmoc-G-Gem; critical aggregation concentration determination; CD and XRD spectra of control groups; and Alamar blue and live dead assays for the determination of cellular viability of 4T1 cells treated with Fmoc-AIPs, Fmoc-AIPs with Fmoc-G-Gem, Fmoc-G-Gem, and Gem only. (PDF)

\section{AUTHOR INFORMATION}

\section{Corresponding Authors}

*E-mail: atekinay@unam.bilkent.edu.tr.

*E-mail: mguler@uchicago.edu.

\section{ORCID $\odot$}

Ayse B. Tekinay: 0000-0002-4453-814X

Mustafa O. Guler: 0000-0003-1168-202X

\section{Notes}

The authors declare no competing financial interest.

\section{ACKNOWLEDGMENTS}

The authors thank M. Guler for help in TEM imaging. This work is partially supported by TUBITAK and TUBA. M.S.E. and G.C.C. were supported by a TUBITAK-BIDEB PhD fellowship.

\section{ABBREVIATIONS}

Fmoc, 9-fluorenylmethoxycarbonyl; HBTU, 2-(1H-benzotriazol-1-yl)-1,1,3,3-tetramethyluronium hexafluorophosphate; TBTU, O-(benzotriazol-1-yl)-N,N,N', $N^{\prime}$-tetramethyluronium tetrafluoroborate; DIEA, N,N- diisopropylethylamine; TFA, trifluoroacetic acid; TIS, triisopropylsilane; DMSO, dimethyl sulfoxide

\section{REFERENCES}

(1) Jia, F., Liu, X., Li, L., Mallapragada, S., Narasimhan, B., and Wang, Q. (2013) Multifunctional nanoparticles for targeted delivery of immune activating and cancer therapeutic agents. J. Controlled Release $172,1020-1034$.

(2) Wicki, A., Witzigmann, D., Balasubramanian, V., and Huwyler, J. (2015) Nanomedicine in cancer therapy: Challenges, opportunities, and clinical applications. J. Controlled Release 200, 138-157.

(3) Eskandari, S., Guerin, T., Toth, I., and Stephenson, R. J. (2016) Recent advances in self-assembled peptides: Implications for targeted drug delivery and vaccine engineering engineering. Adv. Drug Delivery Rev., DOI: 10.1016/j.addr.2016.06.013.

(4) Mandal, D., Shirazi, A. N., and Parang, K. (2014) Self-Assembly of peptides to nanostructures. Org. Biomol. Chem. 12, 3544-3561.

(5) Cui, H., Webber, M. J., and Stupp, S. I. (2010) Self-Assembly of Peptide Amphiphiles: From Moelcules to Nanostructures to Biomaterials. Biopolymers 94, 1-18.

(6) Tian, R., Wang, H., Niu, R., and Ding, D. (2015) Journal of Colloid and Interface Science Drug delivery with nanospherical supramolecular cell penetrating peptide - taxol conjugates containing a high drug loading. J. Colloid Interface Sci. 453, 15-20.

(7) Eldar-boock, A., Polyak, D., Scomparin, A., and Satchi-fainaro, R. (2013) Nano-sized polymers and liposomes designed to deliver combination therapy for cancer. Curr. Opin. Biotechnol. 24, 682-689.

(8) Liang, J., Wu, W.-L., Xu, X.-D., Zhuo, R.-X., and Zhang, X.-Z. (2014) $\mathrm{pH}$ responsive micelle self-assembled from a new amphiphilic peptide as anti-tumor drug carrier. Colloids Surf., B 114, 398-403.

(9) Zhang, P., Cheetham, A. G., Lin, Y., and Cui, H. (2013) SelfAssembled Tat Nanofibers as E ffective Drug Carrier and Transporter. ACS Nano 7, 5965-5977.

(10) Soukasene, S., Toft, D. J., Moyer, T. J., Lu, H., Lee, H., Standley, S. M., Cryns, V. L., and Stupp, S. I. (2011) Antitumor Activity of Peptide Amphiphile Nanofiber-Encapsulated Camptothecin. ACS Nano 5, 9113-9121.

(11) Le, U. M. (2015) Advancement in Gemcitabine Delivery for Cancer Treatment. Springer Int. Publ. 46, 51-54.

(12) Bildstein, L., Dubernet, C., and Couvreur, P. (2011) Prodrugbased intracellular delivery of anticancer agents. Adv. Drug Delivery Rev. 63, 3-23.

(13) Wang, S., Placzek, W. J., Stebbins, J. L., Mitra, S., Noberini, R., Koolpe, M., Zhang, Z., Dahl, R., Pasquale, E. B., and Pellecchia, M. (2012) Novel targeted system to deliver chemotherapeutic drugs to EphA2-expressing cancer cells. J. Med. Chem. 55, 2427-2436.

(14) Satsangi, A., Roy, S. S., Satsangi, R. K., Tolcher, A. W., Vadlamudi, R. K., Goins, B., and Ong, J. L. (2015) Biomaterials Synthesis of a novel, sequentially active-targeted drug delivery nanoplatform for breast cancer therapy. Biomaterials 59, 88-101.

(15) Heinemann, V. (2005) Gemcitabine in metastatic breast cancer. Expert Rev. Anticancer Ther. 5, 429-43.

(16) Tripathy, D. (2002) Overview: gemcitabine as single-agent therapy for advanced breast cancer. Clin. Breast Cancer 3, 8-11.

(17) Qu, G., and Perez, E. A. (2002) Gemcitabine and targeted therapy in metastatic breast cancer. Semin. Oncol. 29, 44-52. 
(18) Carmichael, J. (1995) Advanced breast cancer: A phase II trial with gemcitabine. J. Clin. Oncol. 13, 2731-2736.

(19) Toschi, L., Finocchiaro, G., Bartolini, S., Gioia, V., and Cappuzzo, F. (2005) Role of gemcitabine in cancer therapy. Future Oncol. 1, 7-17.

(20) Moysan, E., Bastiat, G., and Benoit, J. (2013) Gemcitabine versus Modified Gemcitabine: A Review of Several Promising Chemical Modifications. Mol. Pharmaceutics 10, 430-444.

(21) Sun, T., Zhang, Y. S., Pang, B., Hyun, D. C., Yang, M., and Xia, Y. (2014) Engineered Nanoparticles for Drug Delivery in Cancer Therapy Angewandte. Angew. Chem., Int. Ed. 53, 12320-12364.

(22) Xu, Y., Geng, J., An, P., Xu, Y., Huang, J., Lu, W., Liu, S., and Yu, J. (2015) Cathepsin B-sensitive cholesteryl hemisuccinate-gemcitabine prodrug nanoparticles: enhanced cellular uptake and intracellular drug controlled release. RSC Adv. 5, 6985-6992.

(23) Dasari, M., Acharya, A. P., Kim, D., Lee, S., Lee, S., Rhea, J., Molinaro, R., and Murthy, N. (2013) H-gemcitabine: a new gemcitabine prodrug for treating cancer. Bioconjugate Chem. 24, 4-8.

(24) Wang, W., Li, C., Zhang, J., Kong, D., and Dong, A. (2014) Tailor-made gemcitabine prodrug nanoparticles from well-defined drug-polymer amphiphiles prepared by controlled living radical polymerization for cancer chemotherapy. J. Mater. Chem. B 2, 18911901.

(25) Khare, V., Sakarchi, W. Al, Gupta, P. N., Curtis, A. D. M., and Hoskins, C. (2016) Synthesis and characterization of TPGS gemcitabine prodrug micelles for pancreatic cancer therapy. RSC Adv. 6, 60126-60137.

(26) Smith, B. A. M., Williams, R. J., Tang, C., Coppo, P., Collins, R. F., Turner, M. L., Saiani, A., and Ulijn, R. V. (2008) FmocDiphenylalanine Self Assembles to a Hydrogel via a Novel Architecture Based on pi-pi Interlocked b -Sheets. Adv. Mater. 20, $37-41$.

(27) Adler-Abramovich, L., Reches, M., Sedman, V. L., Allen, S., Tendler, S. J. B., and Gazit, E. (2006) Thermal and chemical stability of diphenylalanine peptide nanotubes: implications for nanotechnological applications. Langmuir 22, 1313-1320.

(28) Cinar, G., Ceylan, H., Urel, M., Erkal, T. S., Tekinay, A. B., Guler, M. O., Deniz Tekin, E., and Dâna, A. (2012) Amyloid Inspired Self-Assembled Peptide Nano fi bers. Biomacromolecules 13, 33773387.

(29) Cinar, G., Orujalipoor, I., Su, C. J., Jeng, U. S., Ide, S., and Guler, M. O. (2016) Supramolecular Nanostructure Formation of Coassembled Amyloid Inspired Peptides. Langmuir 32, 6506-6514.

(30) Singh, V., Snigdha, K., Singh, C., Sinha, N., and Thakur, A. K. (2015) Understanding the self-assembly of Fmoc-phenylalanine to hydrogel formation. Soft Matter 11, 5353-5364.

(31) Hamley, I. W. (2007) Peptide Fibrillization Angewandte. Angew. Chem., Int. Ed. 46, 8128-8147.

(32) Pashuck, E. T., Cui, H., and Stupp, S. I. (2010) Tuning Supramolecular Rigidity of Peptide Fibers through Molecular Structure. J. Am. Chem. Soc. 132, 6041-6046.

(33) Wu, C., Scott, J., and Shea, J. (2012) Binding of Congo Red to Amyloid Protofibrils of the Alzheimer Ab9-40 Peptide Probed by Molecular Dynamics Simulations. Biophys. J. 103, 550-557.

(34) Derakhshandeh, K., and Fathi, S. (2012) Role of chitosan nanoparticles in the oral absorption of Gemcitabine. Int. J. Pharm. 437, $172-177$.

(35) Hardy, J. G., Amend, M. N., Geissler, S., Lynch, M., and Schmidt, C. E. (2015) molecular polymers for biomedical applications: electrochemically enhanced drug delivery. J. Mater. Chem. B 3, 50055009.

(36) Gerweck, L. E., Vijayappa, S., and Kozin, S. (2006) Tumor pH controls the in vivo efficacy of weak acid and base chemotherapeutics. Mol. Cancer Ther. 5, 1275-1279.

(37) Chen, M. C., Tsai, H. W., Liu, C. T., Peng, S. F., Lai, W. Y., Chen, S. J., Chang, Y., and Sung, H. W. (2009) A nanoscale drugentrapment strategy for hydrogel-based systems for the delivery of poorly soluble drugs. Biomaterials 30, 2102-2111.
(38) Li, C., Shan, S., Braun, R. D., Hu, K., Lin, P., Dewhirst, M. W., Huang, Q., and Lanzen, J. (2000) Initial Stages of Tumor Cell-Induced Angiogenesis: Evaluation Via Skin Window Chambers in Rodent Models. J. Natl. Cancer Inst. 92, 143-147.

(39) de Sousa Cavalcante, L., and Monteiro, G. (2014) Gemcitabine: Metabolism and molecular mechanisms of action, sensitivity and chemoresistance in pancreatic cancer. Eur. J. Pharmacol. 741, 8-16.

(40) Galler, K. M., Aulisa, L., Regan, K. R., D’Souza, R. N., and Hartgerink, J. D. (2010) Self-assembling multidomain peptide hydrogels: designed susceptibility to enzymatic cleavage allows enhanced cell migration and spreading. J. Am. Chem. Soc. 132, 3217-3223.

(41) Jun, H. W., Yuwono, V., Paramonov, S. E., and Hartgerink, J. D. (2005) Enzyme-mediated degradation of peptide-amphiphile nanofiber networks. Adv. Mater. 17, 2612-2617.

(42) Cinar, G., Ozdemir, A., Hamsici, S., Gunay, G., Dana, A., Tekinay, A. B., and Guler, M. O. (2017) Local delivery of doxorubicin through supramolecular peptide amphiphile nanofiber gels. Biomater. Sci. 5, 67-76.

(43) Zengin, A., Cinar, G., and Guler, M. O. (2017) Controlled enzymatic stability and release characteristics of supramolecular chiral peptide amphiphile nanofiber gels. Curr. Appl. Phys. 17, 785-792.

(44) Fonseca, K. B., Granja, P. L., and Barrias, C. C. (2014) Engineering proteolytically-degradable artificial extracellular matrices. Prog. Polym. Sci. 39, 2010-2029.

(45) Giano, M. C., Pochan, D. J., and Schneider, J. P. (2011) Controlled biodegradation of Self-assembling b-hairpin Peptide hydrogels by proteolysis with matrix metalloproteinase-13. Biomaterials $32,6471-6477$. 